CASE REPORT

\title{
Transient cold nodule of the thyroid due to localized postpartum thyroiditis
}

\author{
Rafael Luboshitzky ${ }^{1,3}$, Gali Qupti ${ }^{1}$, ${\text { Abraham } \text { Ishai }^{1} \text { and Muralee Dharan }}^{2}$ \\ ${ }^{1}$ Endocrine Institute and ${ }^{2}$ Department of Cytopathology, Haemek Medical Center, Afula, Israel and ${ }^{3}$ The B Rappaport Faculty of Medicine, \\ Technion-Israel Institute of Technology, Haifa, Israel
}

(Correspondence should be addressed to R Luboshitzky, Endocrine Institute, Haemek Medical Center, Afula 18101, Israel)

\begin{abstract}
A 27-year-old woman with no previous personal or family history of thyroid disease was referred to us for the evaluation of thyroid nodule, five months postpartum. Thyroid scintigraphy demonstrated a left cold nodule. Fine needle aspiration cytology of the nodule showed a mixture of colloid, follicular cells and lymphocytes, suggesting lymphocytic thyroiditis. Thyroid function tests were normal and thyroid autoantibodies were negative.

After two months the thyroid nodule was not palpated and thyroid scintigraphy returned to normal. Thyroid function tests remained normal twelve months after delivery.

These findings suggest that postpartum thyroiditis may present as a localized transient form and should be considered in the differential diagnosis of painless solitary nodule that appears postpartum.
\end{abstract}

European Journal of Endocrinology 138 562-564

\section{Introduction}

Postpartum thyroiditis (PPT) is a syndrome of thyroid dysfunction that occurs in the first year after delivery. The prototypic case has three phases: hyperthyroidism, hypothyroidism and recovery (1-6). In some patients the thyrotoxic or the hypothyroid phase either does not occur, or is not recognized. Although recovery is usual, recurrent episodes of hypothyroidism and permanent hypothyroidism are found in about $25 \%$ of patients observed for as long as four years (7). Symptoms are often mild and nonspecific in the early thyrotoxic phase and in the hypothyroid phase which occur 3-8 months after delivery $(8,9)$. However, there is one physical finding that is quite common: painless diffuse enlargement of the thyroid gland (5). This mild thyroid enlargement is due to lymphocytic infiltration of the thyroid gland (6).

The occurrence of PPT as a transient single thyroid nodule has not been described so far. We herein report a case of PPT in which the onset of the disease took place five months after delivery, presenting as a single thyroid nodule without evidence of thyrotoxic or hypothyroid phases, and disappearance of the thyroid nodule two months later.

\section{Case report}

A 27-year-old woman with no personal or family history of thyroid disorders, presented with a cervical mass which she noticed on palpation, five months after normal delivery. Physical examination revealed a left non-tender thyroid nodule $2 \times 2 \mathrm{~cm}$. Laboratory examination showed an erythrocyte sedimentation rate of $14 \mathrm{~mm} / \mathrm{h}$, serum free thyroxine $\left(\mathrm{FT}_{4}\right)$ levels of $16.3 \mathrm{pmol} / \mathrm{l}$ (normal values $8.8-22.7 \mathrm{pmol} / \mathrm{l}$ ), and thyroid-stimulating hormone (TSH) levels of $1.2 \mathrm{mU} / \mathrm{l}$ (normal values $0.2-3.8 \mathrm{mU} / \mathrm{l}$ ). Tests for the determination of autoantibodies to human thyroid peroxidase (TPO), anti-TPO (RIA kit, Sorin Biomedica Diagnostics, Saluggia, Vercelli, Italy) and to human thyrogobulin (hTg), IgG to hTg (Immunoradiometric Assay Kit, Sorin Medica Diagnostics) were negative. Thyroid scintigraphy was performed after the intravenous injection of $5 \mathrm{mCi} \mathrm{Tc}-99 \mathrm{mO} 4$ and demonstrated a cold area representing the palpable nodule (Fig. 1A). Ultrasonography revealed a solid thyroid nodule measuring $25 \times 22 \mathrm{~mm}$. Fine needle aspiration (FNA) cytology of the thyroid nodule showed colloid mixed with follicular cells, lymphocytes and macrophages. Some of the follicular cells were degenerated. Oncocytic metaplasia and fibrosis were absent (Fig. 2). The patient received no treatment. Two months later, the thyroid nodule was not palpated. Repeat thyroid scintigraphy and ultrasonography showed normal symmetrical lobes (Fig. 1B). Serum $\mathrm{FT}_{4}$ and TSH levels at 3, 6, 9 and 12 months after delivery remained normal $(15.1,16.3$, 17.8, $17.3 \mathrm{pmol} / \mathrm{l}$ respectively for $\mathrm{FT}_{4}$ and 1.8, 1.6, 0.7, $0.8 \mathrm{mU} / \mathrm{l}$ respectively for TSH). 


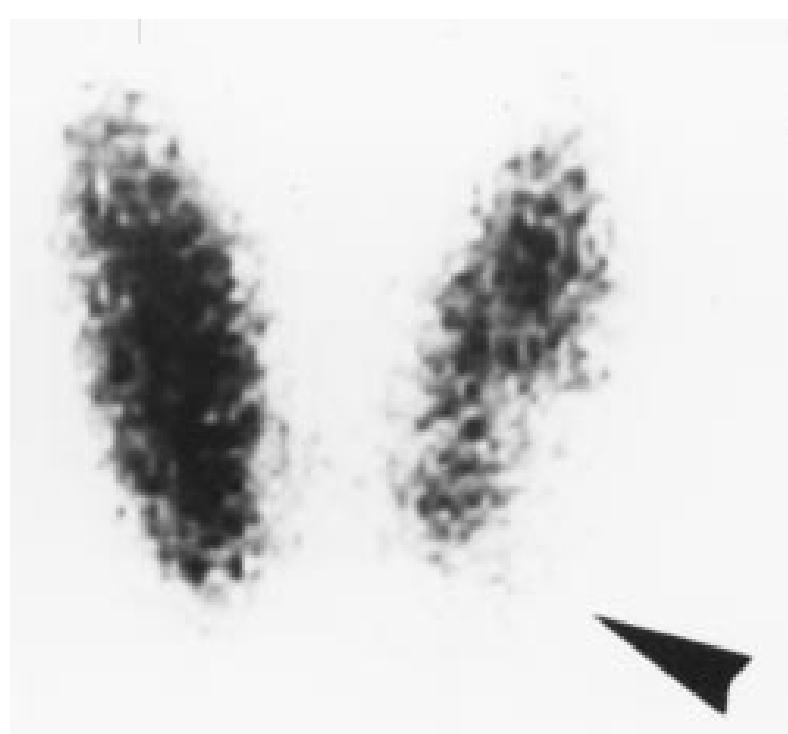

A

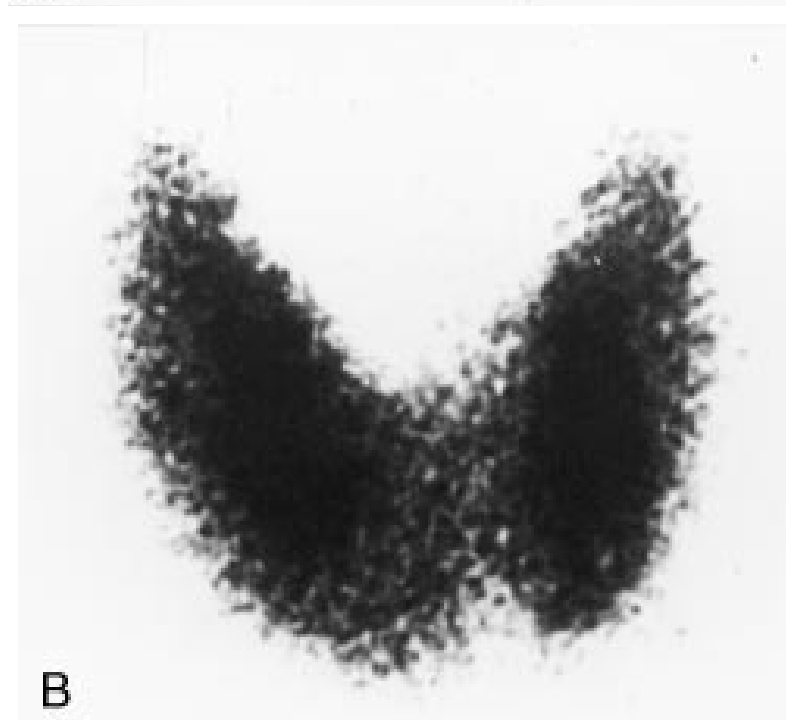

Figure 1 A 27-year-old woman presented with a painless left thyroid nodule five months after delivery. Scintigraphy revealed a discrete cold area in the left lobe of the thyroid gland consistent with the palpable nodule $(A)$. Two months later, the nodule was no longer palpable and scintigraphy demonstrated a normal thyroid gland (B).

Twelve months after delivery, the patient was well, her thyroid gland size was normal and she received no treatment.

\section{Discussion}

The patient described in this report presented with a painless solitary thyroid nodule. The differential diagnosis included carcinoma of the thyroid, lymphoma (non-Hodgkin's as well as primary Hodgkin's disease of the thyroid), sarcoma, metastases to the thyroid, localized bleeding, Hashimoto's thyroiditis, silent thyroiditis and localized subacute thyroiditis $(8-13)$. Since the symptoms and signs of the thyrotoxic and the hypothyroid phases are usually mild, the clinician should be aware of the painless diffuse enlargement of the thyroid gland appearing after delivery, which may be the sole physical finding of PPT (5). Thyroid enlargment in PPT is due to focal or diffuse lymphocytic infiltration and, together with follicular destruction of varying degrees, account for thyroid dysfunction (6). Unlike classic cases of PPT, our patient had a single thyroid nodule, negative tests for antithyroid antibodies and normal thyroid functions, thus raising the possibility of thyroid neoplasm. A non-autoimmune inflammatory reaction was also a possibility in our patient. However, lymphocytic infiltration, follicular degeneration and normal appearance of follicular cells in FNA smears suggested a localized form of autoimmune thyroid disease. In Hashimoto's thyroiditis, lymphocytes are a very prominent component of the aspirate together with significant epithelial atypia. The population of lymphocytes present in Hashimoto's thyroiditis is usually a mixture of lymphocytes of different maturation $(5,10)$. This is in contrast to a uniform population of lymphocytes and lack of colloid seen in malignant lymphoma (10) or lymphocytes mixed with Reed-Sternberg cells observed in Hodgkin's disease of the thyroid (13). Unlike classic chronic autoimmune thyroiditis, however, in PPT or in silent thyroiditis oncocytic metaplasia is lacking, follicular atrophy is minimal or absent and fibrosis is very mild or absent $(5,8,10)$. In our patient, cytology revealed focal lymphocytic infiltration, minimal follicular cells degeneration, lack of oncocytic metaplasia and no fibrosis, suggesting lymphocytic thyroiditis as seen in PPT. Although tests for antithyroid antibodies were negative in our patient, yet the diagnosis of a localized form of PPT or silent thyroiditis was very likely since, in PPT and in silent thyroiditis, only $25-41 \%$ of patients have serum antithyroglobulin antibodies and $60-85 \%$ have antithyroid peroxidase antibodies $(8,9,14,15)$. Cytological findings, together with regression of the thyroid nodule and resolution of the cold area on thyroid scintigraphy, excluded the possibility of neoplasms or Hashimoto's thyroiditis and confirmed the diagnosis of localized painless thyroiditis in our patient. The fact that our patient had negative thyroid autoantibodies suggests the possible diagnosis of focal subacute thyroiditis. However, normal sedimentation rate and lack of neck pain and tenderness makes this diagnosis less likely (12). Currently, PPT is considered to be identical to silent thyroiditis and the term PPT is used for patients who develop silent thyroiditis in the postpartum period $(6,8)$. As this is the first reported case of transient thyroid nodule occurring in postpartum thyroiditis, a word of caution is appropriate here. It it possible that the thyroid nodule may have temporarily regressed. Patients like the one described here should be followed to ensure that a 


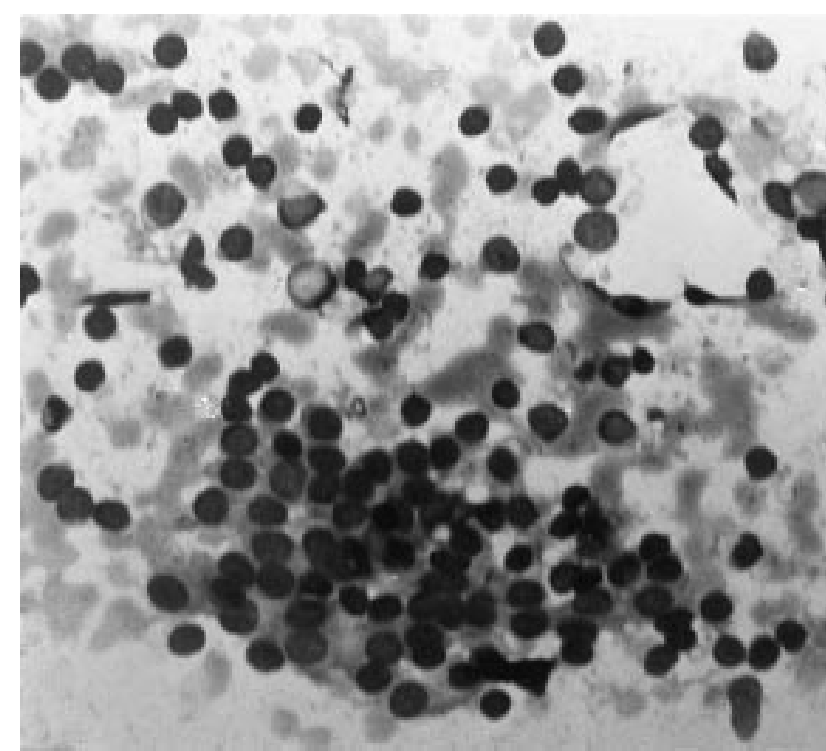

Figure 2 FNA smear from thyroid nodule showing a few unremarkable follicular cells in a background of lymphocytes and isolated macrophages. (Papanicolaou stain; magnification $\times 400$ ).

thyroid nodule does not reappear. Further studies are needed to elucidate the frequency of postpartum thyroiditis appearing as a transient thyroid nodule.

In conclusion, localized postpartum thyroiditis should be considered in the differential diagnosis of painless thyroid nodule that appears after delivery. Cytological diagnosis was of the utmost importance in establishing the diagnosis of localized PPT and in avoiding unnecessary surgery.

\section{Acknowledgements}

The authors wish to thank Mrs Shoshana Lordian for her technical assistance and Mrs Frances Nachmani for her excellent secretarial assistance.

\section{References}

1 Amino N, Mori H, Iwatani Y, Tanizawa O, Kawashima M, Tsuge I, Ibaragi K, Kumahara Y \& Miyai K. High prevalence of transient postpartum thyrotoxicosis and hypothyroidism. New England Journal of Medicine 1982306 849-859.
2 Stagnaro-Green A, Sheila H, Cobin RH, El-Harazy E, AlvarezMarfany M \& Davies TF. Detection of at-risk pregnancy by means of highly sensitive assays for thyroid autoantibodies. Journal of the American Medical Association 1990264 1422-1425.

3 Stagnaro-Green A, Roman SH, Cobin RH, El-Harazy E, Wallenstein S \& Davies TF. A prospective study of lymphocyte initiated immunosuppression in normal pregnancy: evidence of a T-cell etiology for postpartum thyroid dysfunction. Journal of Clinical Endocrinology and Metabolism 199274 645-653.

4 Walfish PG, Meyerson J. Provias JP, Vargas MT \& Papain ER. Prevalence and characteristics of postpartum thyroid dysfunction: results of a survey from Toronto, Canada. Journal of Endocrinological Investigation 199215 265-272.

5 Emerson $\mathrm{CH}$. Thyroid disease during and after pregnancy. In Werner and Ingbar's The Thyroid - A Fundamental and Clinical Text, edn 7, pp 1021-1031. Eds LE Braverman \& RD Utiger. Philadelphia: Lippincott-Raven Publishing, 1996.

6 Mizukami Y, Mighigishi T, Nonomura A. Hashimoto T, Nakamura S, Tonami N \& Takezakura E. Postpartum thyroiditis. A clinical, histologic and immuno-pathologic study of 15 cases. American Journal of Clinical Pathology 1993100 200-205.

7 Othman S, Phillips DIW, Parkes AB, Richards CJ. Harris B, Fung H, Darke C, John R, Hall R \& Lazarus JH. A long-term follow up of postpartum thyroiditis. Clinical Endocrinology 199032 559-564.

8 Amino $\mathrm{N} \&$ Tada $\mathrm{H}$. Autoimmune thyroid disease/thyroiditis. In Endocrinology, edn 3, pp 726-741. Ed LJ DeGroot. Philadelphia: Saunders Company, 1995.

9 Lazarus JH. Silent thyroiditis and subacute thyroiditis. In Werner and Ingbar's The Thyroid - A Fundamental and Clinical Text, edn 7 , pp 577-591. Eds LE Braverman \& RD Utiger. Philadelphia: Lippincott-Raven Publishing, 1996.

10 Atkinson BF. Fine needle aspiration of the thyroid. In Pathobiology of the Parathyroid and Thyroid Glands, pp 166-199. Eds VD Livolsi \& RA DeLellis. Baltimore: Williams and Wilkins, 1993.

11 Hardoff R, Bar-Shalom R, Dharan M \& Luboshitzky R. Hodgkin's disease presenting as a solitary thyroid nodule. Clinical Nuclear Medicine $19952037-41$.

12 Hardoff R, Baron E, Sheinfeld M \& Luboshitzky R. Localized manifestations of subacute thyroiditis presenting as solitary transient cold thyroid nodules: a report of 11 patients. Clinical Nuclear Medicine 199520 981-984.

13 Luboshitzky R, Dharan M, Nachtigal M, Rosen G \& Honigman J. Syncytial variant of nodular sclerosing Hodgkin's disease presenting as a thyroid nodule. Acta Cytologica 199539 543546.

14 Mizukami Y, Michigishi TI, Hashimoto T, Tonami N, Hisaba K, Matsubara F \& Takazakura E. Silent thyroiditis: a histologic and immunohistochemical study. Human Pathology 198819 423431.

15 Marqusee E, Hill JA \& Mandel SJ. Thyroiditis after pregnancy loss. Journal of Clinical Endocrinology and Metabolism 199781 24552457.

Received 1 December 1997

Accepted 6 January 1998 